\title{
Toward a New Concept of a Future Generation of Comparison Shopping Engines
}

\author{
Laghmari Ghizlane \\ Laboratory of Computer \\ Sciences, Computers and \\ Telecommunications FST \\ Tangier, Morocco
}

\author{
Azmani Abdellah \\ Laboratory of Computer \\ Sciences, Computers and \\ Telecommunications FST \\ Tangier, Morocco
}

\author{
Aitkbir M'hamed \\ Laboratory of Computer \\ Sciences, Computers and \\ Telecommunications FST \\ Tangier, Morocco
}

\begin{abstract}
In the context of the new era of marketing and Digital transformations [1][2], the multiple means of advertising and the unrestricted creation of needs joined to the excessive online temptations are constantly overwhelming the consumer with offers that he is becoming unable to evaluate [3]. Accordingly, he finds himself turning to comparison shopping engines (CSEs). Although, multiple surveys have declared that most consumers show major dissatisfaction with these engines' services.[4][5][6].

The progress of artificial intelligence is transforming all ecommerce's practices therefor it becomes essential to think of a new concept of approaching CSEs. Hence, this article presents an innovative concept presenting a Smart Virtual Consumer Assistant (SVCA) aggregated into an intelligent digital eco-system specific to online sales. Such an assistant will be able first to help the consumer in innovative, comprehensive and adapted way to his needs, his profile and his purchasing ethical values during all his consumption processes, and second to protect him from making any purchases that may present either a physical or a digital harm.
\end{abstract}

\section{General Terms}

Artificial Intelligence, e-commerce, Multi-agent system, shopbot.

\section{Keywords}

Comparison shopping engines, Consumer rights, Ethics of consumption, virtual consumer assistant.

\section{INTRODUCTION}

In recent years, with the ubiquity of the Internet, the ease of online payment and the widespread of social networks, the consumer, being reachable at all time, can be tempted and encouraged to do a business transaction at any time.

A great number of brands have focused their resources on prospecting techniques to push or manipulate the final customer to purchase as much as possible for the sole objective of increasing their profits [7].

This unidirectional approach a bit extreme joined to a bad use of digital data, collected mostly without the knowledge of consumers, has caused several unhealthy practices [6]that continues to disrupt the consumption behavior of individuals and which led to the following observations:

- the disorientation and purchase confusion of the consumer;

- $\quad$ the mistrust of the consumer;

- the dissatisfaction of the consumer.
This article begins by detailing the 3 previous observations and presents the multiple limits of the existing CSEs. It then sets out the fundamentals of the new concept to be proposed by the article while giving an idea of its feasibility and implementation as well as its possible perspectives.

\section{THE NEGATIVE EFFESTS OF UNETHICAL MARKETING PARTICES}

This section details the multiple negative observations exposed above.

\subsection{The disorientation and purchase confusion of the consumer}

The consumer's disorientation and purchase confusion are primarily caused by information overload[8] and unethical marketing practices such as confusing and manipulating marketing techniques[9].

Consumers' buying confusion is defined by "a conscious mind of a cognitive and behavioral dimension that occurs either before or after the purchase and is manifested by his inability to finalize a judgment, a choice or a decision on a product or brand". [10][11][12].

First this phenomenon leads to a symptom called "paralysis of the analysis". It is defined as an overestimation or an excessive reflection of a situation, so that a decision becomes challenging to be correctly evaluated with clear discernment, and ends up being delicate to be taken [13].

Secondly, this phenomenon, despite its alliance with a decision blocking, once associated with the unethical marketing pressure can lead the consumer towards extremely unreasonable buying choices[3] (useless purchases, regretted purchases, compulsive purchases, excessive purchases, suspicious or dangerous purchases, etc.) which can have considerable material, physical, psychological, personal and professional damages[11]. 


\subsection{Consumer mistrust}

The digitization of sales raises challenging problematics regarding the use of consumers' personal data by corporations. While trust is one of the bases of customer's loyalty, it becomes difficult to maintain when the e-merchant tracks the consumer through several technologies and digital objects in order to know and predict his behaviors, his desires, his weaknesses, ... so as to encourage him to buy more.

The multitude of means (smart devices ${ }^{1}$ ), available and free tools (games, email and messaging services, loyalty cards), social networks (Facebook, Instagram) and technologies (artificial intelligence $^{2}$, big data science ${ }^{3}$ ) easily allow the mining and the processing of personal data. Worse, the user becomes unconsciously a victim in the abuse of his information without measuring the consequences on his purchasing behavior and his consumption's choices. Therefore, based on the data collected, e-merchants obtain a knowledge Eldorado on which they rely to develop methods of prevention, recommendation and marketing manipulation to push their sales even further.

However, with the current movements raising awareness around the importance of digital data privacy and controversies around their unethical abuse, as demonstrated by the scandal of Facebook and Cambridge Analytica [16], it is clear that Internet users are becoming more and more conscious when it comes to their digital identities.

\subsection{Consumer dissatisfaction}

Customers, confused by the on line's recommendations' overload or worried of the way in which e-merchants exploit their personal data, quickly develops a feeling of mistrust, distance and dissatisfaction that can lead to several consequences such as escaping to other competitors, seizing false digital information, breaking up with virtual consumption, writing negative comments, etc.

\section{COMPARISON SHOPPING ENGINES'S INADEQUACIES}

Following the digital and marketing transformations that constantly occur in the consumption experience, as well as the negative impacts of the aforementioned practices, there has been the debut of CSEs in the middle of 1990 as a solution to guide and assist consumers.

The purpose of these comparison shopping engines is to facilitate and control research around all different offers on the web, as well as assist the consumer towards a better choice [17]. However, several questions arise as to whether these comparison shopping engines really meet consumer's demand while respecting his consumption ethical values:

- Do they assist the consumer with transparency and reliability?

- Are their recommendations more in the favor of the consumer, or the e-merchant?

\footnotetext{
Smartphones, tablets, GPS devices, smart TV ...

${ }^{2}$ Artificial intelligence is the set of theories and techniques developing complex computer programs capable of simulating some of the human intelligence features (reasoning, learning ...). [14]

${ }^{3}$ Big Data science is a broad field that refers to the collective processes, theories, concepts, tools and technologies that enable the review, analysis and extraction of valuable knowledge and information from raw data. It is geared toward helping individuals and organizations make better decisions from stored, consumed and managed data.[15]
}

- $\quad$ Do they respect the consumer confidentiality and virtual identity?

- Do they correctly comply with the consumer's specifications in their researches and offers' evaluations?

As an answer, multiple areas of concern are discernible around comparison shopping engines:

1- Incompleteness, Irrelevance and redundancy of information due to an ineffective search routine.[18]

2- Having the price be the prime competitive advantage in the offer's evaluation and ranking which lead to a nonexhaustive recommendation. the consumer finds himself facing a service that doesn't consider his desired research's criteria and restricts him. [5]

3- Standardization of the search and the evaluation process that can come at the expense of differentiation and brand loyalty. [18]

4- Unethical recommendations based mostly on partnerships between the shopping comparison engines and merchants. [5] [19]

5- Lack of transparency and intentional withholding of key information (shipping fees, taxes).

6- Excessive Advertising content. [6]

7- Non consideration of the consumer's consumption ethical values (cruelty free, vegan, ...), sanitary conditions (allergies, diseases, ...) and legal standards consideration in offers' evaluation. It is necessary to remember that in keeping with the current marketing trends, centralized on the customer's serving, the latter should be notified of any offer's legal risks (associated customs' measures, penalties of the consumption of some products), sanitary dangers (toxic substances) [20] as well as the brand's ethical position (whether it is related to the production, the distribution or the marketing of its products).

The respect of these concerns in the evaluation of an offer or in the sensitization of the consumer is becoming indispensable and will definitely increase the purchases [21]and create a relation of fidelity and trust [22] between both sides. However, in spite of the importance of these last, most CSEs aren't aware of their value, and haven't invested in making any changes regarding these concerns.

\section{TOWARDS A NEW GENERATION OF COMPARISON SHOPPING ENGINES}

Recognizing the limits of a solution and the causes of its dysfunction is not always enough, seeking to improve it or replace it is the right way to go. So, in order to tackle the above mentioned shortcomings of the CSEs and to resolve the consumer's disorientation due to inappropriate and nonexhaustive recommendations, it became necessary to think of a new concept. This is even more relevant considering the millennial consumer is becoming more and more demanding for diversified, accurate, reliable, impartial and transparent comparison tools.

In what follows, the article presents the fundamentals of an innovative concept that takes into account the following axes:

1. The consumer mutation from a passive state to an active state. [23]

2. The digital transformations of marketing and e-commerce toward focusing on the consumer's satisfaction. 
3. The inadequacy of the existing shopping comparison engines' methodology: based on a one-way communication only.

\subsection{The rise of a new active consumer}

The current context of digital marketing is constantly changing to suit the consumer's behaviors and needs [24]. The millennial generation, who is becoming more and more curious, demanding, critical and well informed, develops a new behavior that seeks to get deeply involved in the consumption experience [23]. While counting on its exchanges through the various virtual communities and available free information websites it keeps investigating the following processes around its purchases [23][25]:

- The production process: the quality of the raw materials and the constituents, the production conditions, the history and the ethics of the brand (what the brand stands for?) [26] [27] [28].

- The communication strategy: the choice of communication channels (e-commerce websites, social networks, e-mails, etc.), the quantity of the communication, the quality and the credibility of the information, the influence figures used, the respect of the consumer's virtual information, etc.

\subsection{Deep customer relationship is the grail of success}

Between Consumer Relationship Management (CRM) and Social Consumer Relationship Management (SCRM) nowadays marketers are focusing more on gaining and maintaining customers' loyalty than on the concern of achieving more sales. Companies now are carefully trying to establish and build a trust relationship with the consumers by deeply connecting with their precise needs during the buying process:

\section{- Before the purchase:}

- By predicting or creating their needs: they collect as much information as possible about one's profile and expectations and therefore adapting the offers to that.

- By alerting them about current promotional offers.

- By promoting the products in the best suited way to their generation (ex: using social networks and influencers (Youtubers, Instagramers and Bloggers)).

- During the purchase operation:

- By offering virtual assistance to guide them to the appropriate choices while researching.

- By facilitating the purchase process using smart sales channels such as mobile applications, modern electronic payments (bitcoins, etc.) or purchasing directly through social networks (F-commerce on Facebook, the Buy button of Pinterest, etc.).

Post purchase:

- By personalizing the products packaging.

- By offering an after-sales service capable of being attentive to their problems and analyzing their feedbacks and their satisfaction or dissatisfaction.

\subsection{The respect of the consumer, a dimension that takes all its forms}

However, all this effort in maintaining the client's loyalty can't be truly exhaustive if it doesn't listen to the consumer's actual needs and respect his own choices and consumption values while protecting his health and virtual security (the confidentiality of his information's and private life). The current digital marketing transformations [24] consists on creating a certain transparency with the consumer based on a win-win type contract that benefits both parties: merchant and consumer. And for this to be possible, the merchant must respect the wishes and principles of the consumer and aim them in the development of his offers.

\section{THE FUNDAMENTALS OF A SMART VIRTUAL CONSUMER ASSISTANT (SVCA)}

The Smart Virtual Consumer Assistant (SVCA) is an intelligent system that aims to support the consumer in his purchasing activities by providing 5 main assistances, illustrated in Fig 1:

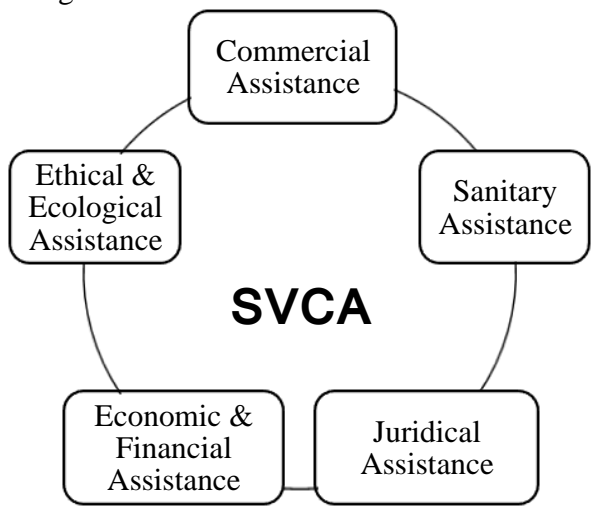

Fig 1 : The major assistances of the SVCA

The 5 assistances and their evaluation's criteria are defined as follows:

\subsection{Commercial assistance}

This service consists first on the investigation of the most exhaustive offers to the purchasing needs expressed by the consumer, and second on the presentation of these offers in a way that provide the most important and adapted information without putting the consumer in a situation of overload. The search of the offers is based on the attributes that the consumer researches in the offer (name of the product, price, color and other technical characteristics) as well as the specifics to his personal profile (purchasing power, age, gender, family situation, etc.).

Then, the classification of these offers applies with the consideration of all the aforementioned attributes and also with the consideration of the customer's consumption values (eco-friendly consumption, legal attitude toward the product's origin, etc.). This classification is applied according to the degree of flexibility and importance the consumer grants to these attributes.

As a result, a list of 5 to 10 offers is displayed gathering the most suitable to the consumer's targeted demands. Such an approach limits the overload of inadequate choices which is mostly frustrating for the consumer [13]. 


\subsection{Sanitary assistance}

In this context, the role of the assistant is manifested in warning the consumer regarding any risk that a product may have on his health. While presenting the final list of offers to the consumer, indicators will be attached to each offer to indicate whether the product respects the health requirements already specified by consumer (example: Hypoallergenic, Organic, Gluten-free, GMO-free, Sugar-free, etc.) or represents a health hazard by the existence of certain products known to be dangerous (strong allergenic substances, dangerous dyes[22], heavy metals[29], etc.) or contains any failures in the production or within distribution process (cold chain breakage, use of nanotechnologies in packaging to increase the shelf life, etc.) [20] [30]. It is something that may or may not be mentioned in the package. Thus, the system unearths this information in the product data sheet, blog posts, electronic journals, forums and social network's publications to alert the consumer so he can make his decision in the most transparent way. Which puts the assistant in a preferred spot as being caring putting forward consumer loyalty.

\subsection{Juridical assistance}

This assistance is around providing legal context protection and warning the consumer of any illegal measure or risk around an offer. He is then notified about the following risks:

- Illegal character of an offer or its commercial illegitimacy: In case the offer provides an illegal product (smuggled product [31], counterfeit product [32], stolen product, expired products, etc.) the consumer will be notified.

- Criminal risks arising from any legislation following the importation, the purchase or the consumption of a product that contains or not an illicit or prohibited substances (customs fees, fines, possibility of the

product's confiscation, possibility of a prison sentence, etc.).

As a result, the consumer will be able to make a conscious decision with respect to the risks that may be incurred.

\subsection{Ethical and ecological assistance}

This assistance stands behind the respect of the consumers' consumption ethical values (vegan consumption [25], consumption of Cruelty-free products [25], environmental protection (recycling, fair trade, etc.), respect of labor right) and religious beliefs (Halal, kosher, etc. [33] ).

Such an assistance saves the consumer the waste of time spent searching products that respects his principles. The classification of the proposed offers to the consumer will take into account his consumption ethical values according to the degree of flexibility and importance he attribute to them.

\subsection{Economic and financial assistance}

During this assistance, the system monitors the consumer's buying habits, his purchasing temperament as well as the relevance of a purchase act and the nature of the object to buy.

The main objective of this assistance is to protect the consumer from a useless purchase or a purchase that may cause him financial problems by warning him about the impulsive nature of the act of purchase or a suspicious aspect about a possible tempting offer, a very attractive advertisement or a potential scam. This assistance also allows him to find bargains not to be missed in respect of his financial potential at a specific time. It can also find him, when necessary, the most appropriate financial means to fund an important and needful purchase.

\section{THE FUNCTIONAL ARCHITECTURE OF THE SMART VIRTUAL CONSUMER ASSISTANT}

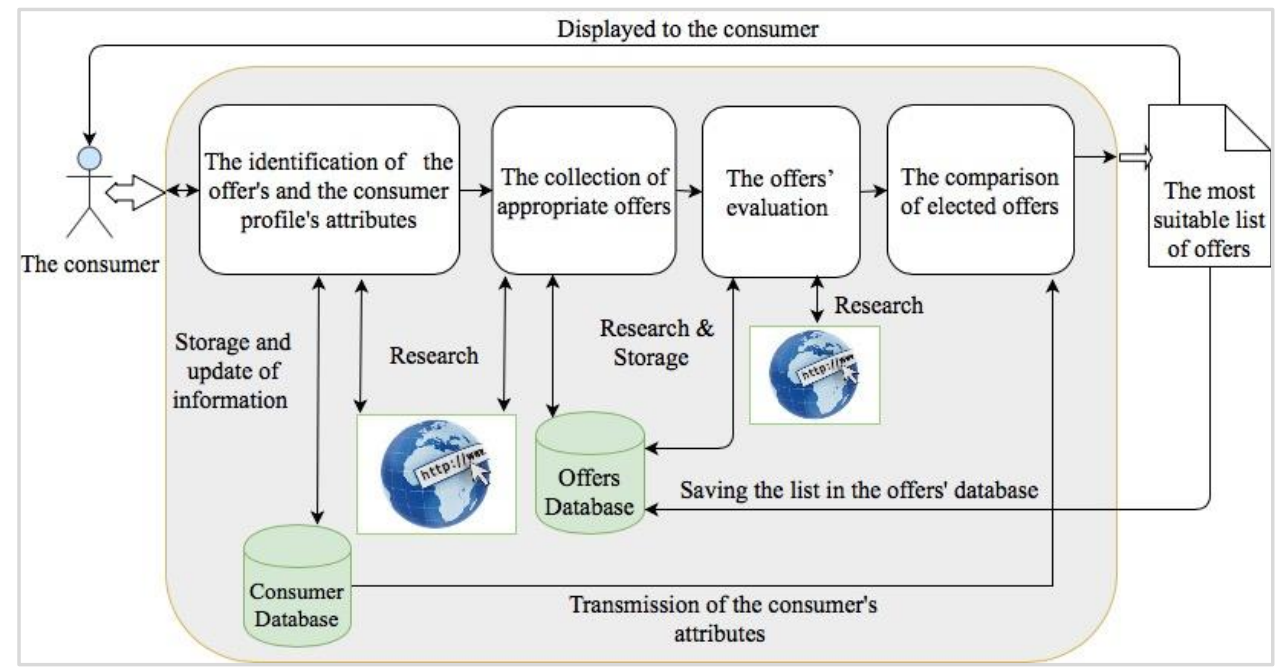

Fig. 2: the different stages of investigating the most adapted offers to the requirements of the consumer

This section presents the global architecture of A Smart Virtual Consumer Assistant. More particularly, the mentoring process of the consumer in his seeking for the exhaustive offer to acquire as illustrated in the Fig.2:

1) The investigation and the identification of the consumer profile's attributes and criteria and those of his sought offer;

2) The collection of the appropriate offers;
3) The offers' evaluation on the basis of the assistances, mentioned in the previous section;

4) The comparison of elected offers.

\subsection{The identification of attributes}

During this first phase, the system is responsible for retrieving information about the user's profile and his sough offer. 
The recovery of the consumer's personal criteria is done at the time of his authentication or gradually thereafter during his logins. It is done through a questioning on his personal information (salary, social status, etc.), his interests, his buying habits, his consumption's ethical and legislative values, his constraints (Allergies, illnesses, etc.) or preferences (Organic, Paraben free, Cruelty-Free, etc.).

It can also be done simultaneously thought the exploitation and the analysis of his purchase history, collected from social networks' databases, such as his tastes, his preferences, his favorite books and videos, his groups of friends, his hobbies, his main recreational and professional activities, his family composition, his social status, etc. [34]. For example, the extraction of information through the consumer's purchase behavior can be done, as developed by Soe-Tsyr Yuan [9], with the analysis of articles that the consumer browses, the order in which these articles are viewed, the time the consumer spent browsing the details of these items, etc. [9].

As for the recovery of the sough offer's criteria and attributes, it is done directly through the formulation of his request around the characteristics of the product and the offer that may interest him as well as the selection of filters (the assistances) that he wishes for the Intelligent Virtual Consumer Assistant to apply in its process.

The personal criteria and attributes of the consumer's profile and those attached to the offer he searches for will be stored in the consumer database, as shown schematically in Fig 2.

\subsection{The collection of appropriate offers}

Once the system has the necessary information on the desired offer, it proceeds to the search and the collection in different sources such as the system database (containing the products of the e-merchant and the offers whose information has been already collected by the system), the online search engines, the comparison shopping engines, the e-merchants and ebidding websites.

Thus, at the end of this phase, an offers' list deemed most compatible with the consumer's desired characteristics will be delivered.

\subsection{The offers' evaluation}

Once the list of offers is collected, the SVCA proceeds in to the

application of several evaluations, relying on the aforementioned assistances.

Each evaluation of a collected offer consists on the attribution of a specific label in relation to its legality, its health situation, its ethical character and its financial aspect.

At the end of this evaluation phase, two possibilities are offered to the consumer, a list of all the founded offers with indicators related to the aforementioned labels and a purged list that contains the offers elected and respectful of its basic criteria. The potential buyer can go perform on each list various filters allowing him to well decide his purchase.

\subsection{The comparison of elected offers}

Following the collection of offers and their evaluation, the comparison phase is initiated. This comparison consists on classifying the offers with the consideration of all the different aforementioned criteria while projecting above the consumer's consumption values according to the degree of tolerance he accorded to them.
During this phase, the Smart Virtual Consumer Assistant performs the comparison of all the offers, collected, evaluated and labelled. Each of the above assistances has been able to assign values to its own criteria. From these, two multicriteria methods, the AHP method ${ }^{4}$ and the TOPSIS method ${ }^{5}$ has been combined. This combination has allowed the generation of a list of orderly offers from the most, to the least consistent with the desires and the profile of the consumer.

The result is a proposal of a list containing from 5 to 10 most adapted offers to the consumer as clarified bellow in section 4.1.

The activity diagrams in the figures Fig. 3 shows the operating process of the SVCA, from the moment the consumer initiates his research for an offer to the display of the final list of offers filtered according to his criteria, motivations and means.

\section{DISCUSSION AROUND THE FEASIBILITY OF THE SMART VIRTUAL CONSUMER ASSISTANT 'S IMPLEMENTATION}

Following the changes in the consuming experience, several researchers[37][38][39] have explored the world of ecommerce or more precisely that of shopping comparison engines by raising the following questions and trying to find their answers:

- Can digital technologies be deployed to help people make better decisions, rather than restricting their ability to do so?

- Would it be possible to find an intelligent solution able to assist the consumer in his purchasing experience with all efficiency and respect of his desires and of his consumption ethical values?

- Could digital intelligence be serving both the client and the e-merchant in a Win Win balance?

The article provides, on his turn, provides an answer to the previous questions by the proposal of an innovative concept of an intelligent virtual purchasing assistant SVCA based on the consideration of the above-mentioned assistances, the elaboration of which involves:

1. The establishment of a digital ecosystem, built around a data center and a social network that's bringing together consumers and socio-economic actors, while aggregating data from several databases (public Data, e-merchant's websites data) or collected through the web.

\footnotetext{
${ }^{4}$ AHP (Analytic Hierarchy Process) is a (Multi criteria decision analysis (MCDA) tool that provides a systematic process for problem structuring, and for subsequently integrating the inherent subjectivity of decision preferences into a rigorous mathematical framework. It can incorporate both quantitative and qualitative criteria into the hierarchical decision structure and also can be extended to a network structure of inner and outer dependence with feedback[35]

${ }^{5}$ TOPSIS (Technique for Order Preference by Similarity to Ideal Solution) is a MCDA method too based on the concept that the chosen alternative should have the shortest geometric distance from the positive ideal solution and the longest geometric distance from the negative ideal solution[36]
} 


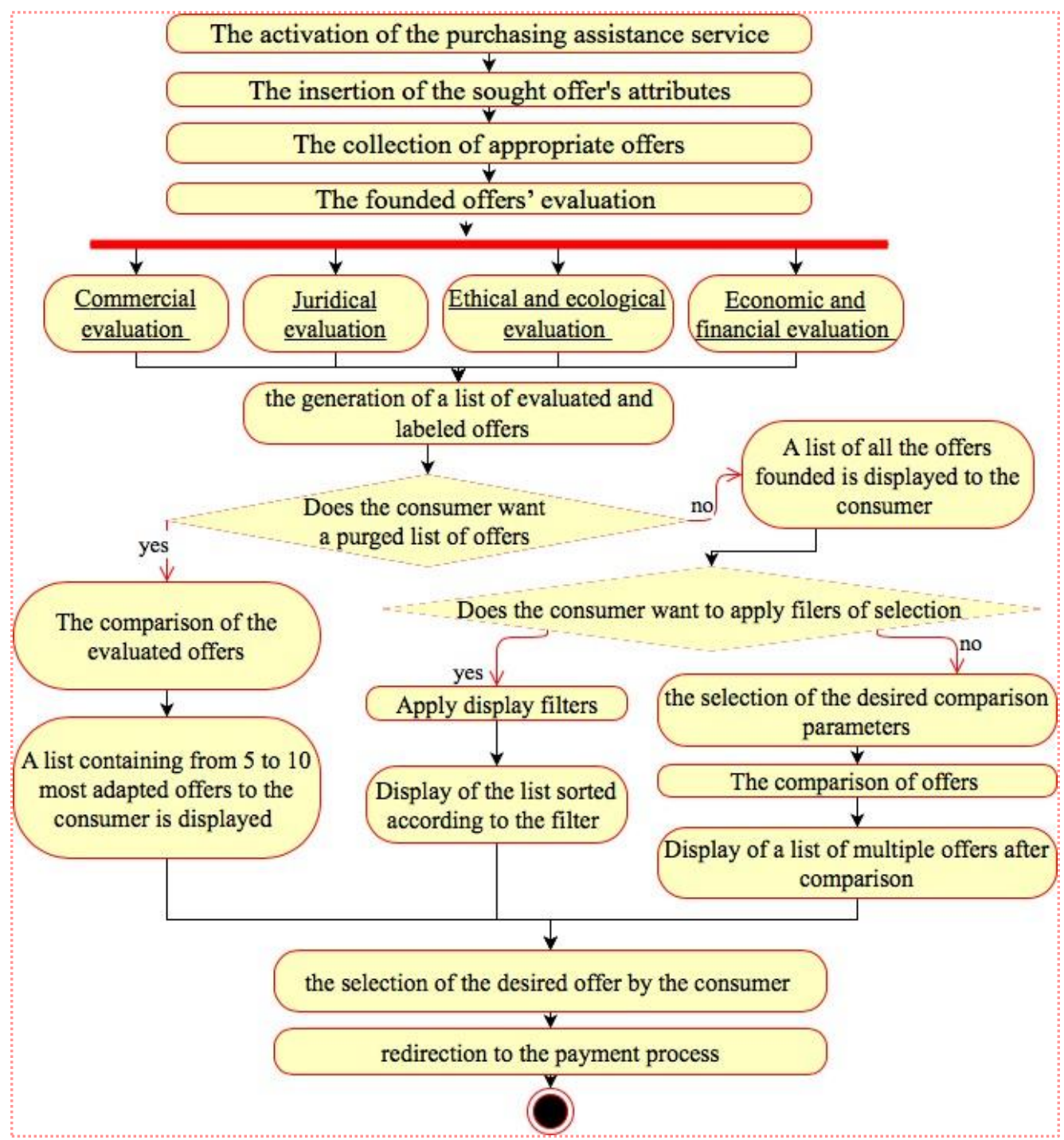

Fig 3: The activity diagram of the consumer's authentication and attributes' identification

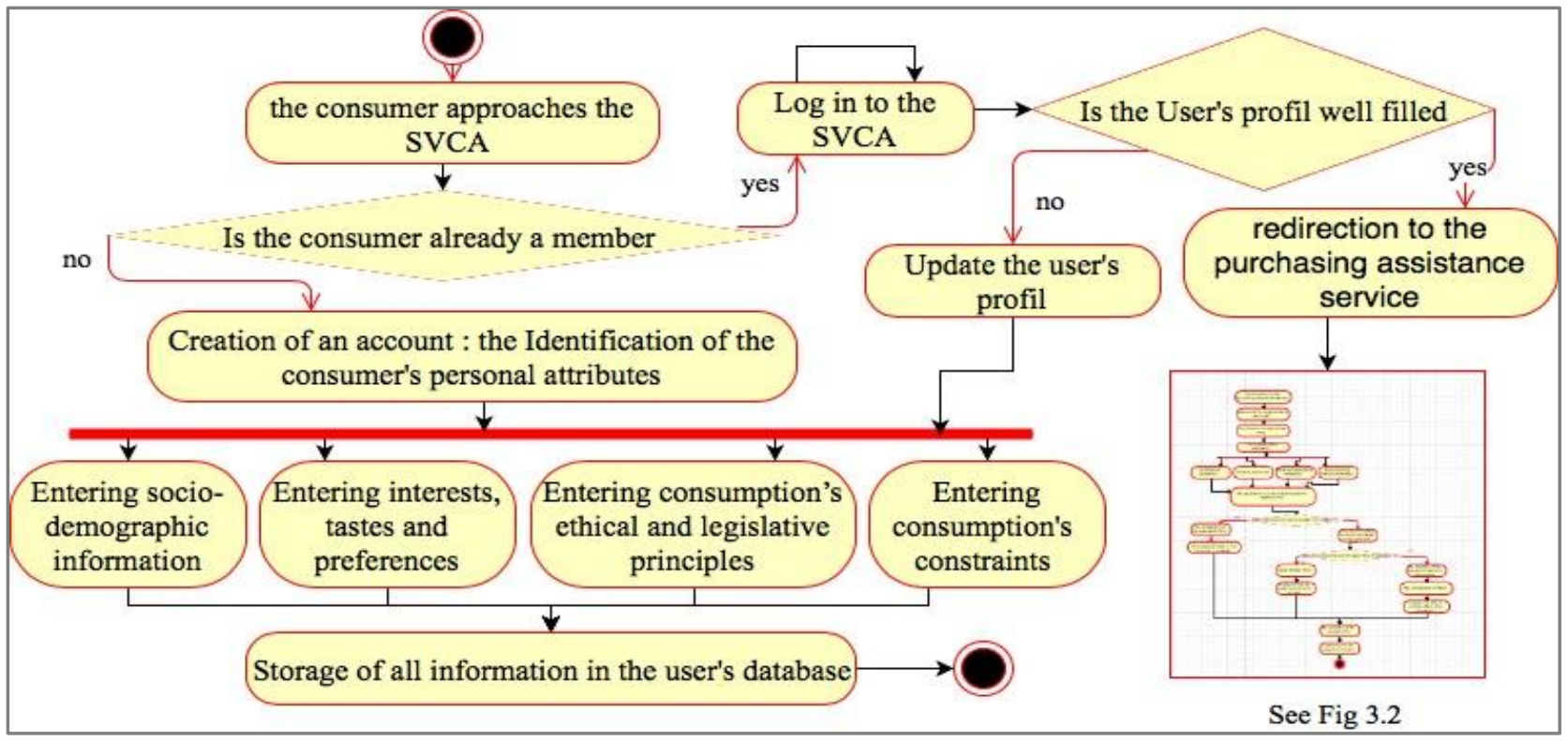

Fig 3.2: The activity diagram of purchasing assistance service 
2. The use of algorithms founded on artificial intelligence techniques and applications capable of processing massive data to better assist, guide and help consumers to operate in an efficient manner, with respect to their identity, their health, their convictions and their values.

Such a digital ecosystem is based on a scalable Big data infrastructure built around a cloud architecture that connects multiple systems thus forming a large network.

The data collection is done in several ways:

- The integration of specific APIs from public or private partner information systems.

- The use of data collection techniques on the internet using web scraping and web crawling technologies.

The data will be processed, interpreted and stored either in structured databases (SQL type) or unstructured one (NoSQL type).

The virtual assistances, aforementioned, operate within the framework of a multi-agent system [40] (MAS) ${ }^{6}$ where each of them is materialized by a specific virtual agent. Each agent represents an assistant who reacts autonomously in his environment while interacting with the other agents according to a predetermined network and whose communication is done via a dedicated ontology. The exchanges between the agents and the various systems forming the cloud of the digital ecosystem, associated with the intelligent virtual consumer assistant, will be based on the principles of the websemantics. Some agents will be built on algorithms based on multi-criteria methods to evaluate and rank offers and a method combining Bayesian networks and fuzzy logic to assess the probability of the risk for SVCA to be wrong and its possibility of doing a bad purchase.

The ecosystem will also use deep-learning algorithms to develop knowledge and to improve his learning reflexes toward the classification of offers especially by learning to spot illicit ones.

\section{CONCLUSION AND PERSPECTIVES}

This article focuses the attention, in the first instance, on the consequences of the consumer's excessive overload with online product's offers, which can introduce a feeling of confusion preventing the customer from having a healthy consumption experience and ruining his loyalty to a brand. [10]

Afterwards, the article discusses the comparison shopping engines as a primary solution to this problem while highlighting their inadequacies that generates serious dissatisfaction from their users. Thereafter, the article presents the encouraging elements to the development of this innovative concept aiming at an almost total assistance of the consumer in his purchasing experience to allow him to take his decisions in the confidence and the total respect of his personal data, his confidentiality, his values, his purchasing power and his health, as well as to avoid him any malicious aspects that may cause him any harm.

The implementation of such a concept is based on an intelligent digital ecosystem that demands integrating several

\footnotetext{
${ }^{6}$ A multi-agent system (MAS) is a set of parallel computer processes, thus of several agents living at the same time, sharing common resources and communicating with each other with rules and relationships. [40]
}

technologies and methods derived from artificial intelligence, such as: multi-agent systems, ontologies, semantic web, multi-criteria analysis, deep-learning and more.

For the moment, this contribution has been presented in its theoretical framework. Future work and publications will focus on the detailed presentation of the different phases of the Echo-system's architectures and its associated Multi-agent system including their ontologies and their artificial intelligence algorithms.

\section{REFERENCES}

[1] A. Carù and B. Cova, "Expériences de consommation et marketing expérientiel," Rev. Fr. Gest., vol. 162, no. 3, pp. 99-113, 2006.

[2] M. Schögel, "Marketing Transformation," Mark. Rev. St Gallen, vol. 32, no. 1, pp. 3-3, Mar. 2015.

[3] V.-W. Mitchell and V. Papavassiliou, "Marketing causes and implications of consumer confusion," J. Prod. Brand Manag., vol. 8, no. 4, pp. 319-342, Aug. 1999.

[4] A. L. Montgomery, K. Hosanagar, R. Krishnan, and K. B. Clay, "Designing a Better Shopbot," Manag. Sci., vol. 50, no. 2, pp. 189-206, 2004.

[5] Mathilde, "Comparateurs de prix : pour ou contre? UGAL," 29-Mar-2011. [Online]. Available: http://fr.ugal.com/blog/les-comparateurs-de-prix. [Accessed: 04-Jan-2018].

[6] A. Bétizeau-Morge and A. Basquin, "Chapitre 22 Psychothérapies comportementales dans les addictions sans substance (jeu pathologique, achats compulsifs)," in Addictologie (3e édition), M. Lejoyeux, Ed. Paris: Content Repository Only!, 2017, pp. 399-407.

[7] G. Lipovetsky, Le Bonheur paradoxal. Essai sur la société d'hyperconsommation, Gallimard. 2006.

[8] M. A. Kamins and F. H. Alpert, "Consumer Brand Confusion: The Prevalence, Cause, and Impact of Misperception of Market Leader and Market Pioneer Brands," in Proceedings of the 1997 World Marketing Congress, Springer, Cham, 2015, pp. 549-549.

[9] "confusion marketing Meaning in the Cambridge English Dictionary." [Online]. Available: https://dictionary.cambridge.org/dictionary/english/confu sion-marketing. [Accessed: 29-May-2018].

[10] L. Allen and J. L. Zaichkowsky, "Understanding Consumer Confusion Online $<$ Superscript $>\bullet</$ Superscript $>$," in Assessing the Different Roles of Marketing Theory and Practice in the Jaws of Economic Uncertainty, Springer, Cham, 2015, pp. 39-44.

[11] V.-W. Mitchell, G. Walsh, and M. Yamin, "Towards a Conceptual Model of Consumer Confusion," ACR North Am. Adv., vol. NA-32, pp. 143-150, 2005.

[12] T. Ghosh, The Cluttered Online Marketplace: Dealing with Confusion of Mobile App Buyers. 2016.

[13] R. Kurien, A. R. Paila, and A. Nagendra, "Application of Paralysis Analysis Syndrome in Customer Decision Making," Procedia Econ. Finance, vol. 11, no. Supplement C, pp. 323-334, Jan. 2014.

[14] É. Larousse, "Encyclopédie Larousse en ligne intelligence artificielle." [Online]. Available: 
http://www.larousse.fr/encyclopedie/divers/intelligence artificielle/187257. [Accessed: 29-May-2018].

[15] S. Fan, R. Y. K. Lau, and J. L. Zhao, "Demystifying Big Data Analytics for Business Intelligence Through the Lens of Marketing Mix," Big Data Res., vol. 2, no. 1, pp. 28-32, Mar. 2015.

[16] "MEPs frustrated by Zuckerberg questioning," $B B C$ News, 22-May-2018.

[17] V. Swaminathan, "The Impact of Recommendation Agents on Consumer Evaluation and Choice: The Moderating Role of Category Risk, Product Complexity, and Consumer Knowledge," J. Consum. Psychol., vol. 13 , no. $1 / 2$, pp. 93-101, 2003.

[18] W. H. Redmond, "The potential impact of artificial shopping agents in e-commerce markets," J. Interact. Mark., vol. 16, no. 1, pp. 56-66, Dec. 2002.

[19] I. COUNE, "Bilan : les limites des sites comparateurs de prix - Consommation - Le Particulier," LeFigaroParticulier.fr, Jan-2013. [Online]. Available: http://leparticulier.lefigaro.fr/jcms/p1_1508282/bilan-leslimites-des-sites-comparateurs-de-prix. [Accessed: 04Jan-2018].

[20] G. Kanny, D. Dano, J.-L. Danan, C. Astier, and S. Lefevre, "Information des consommateurs allergiques et étiquetage : actualités," Rev. Fr. Allergol., vol. 55, no. 7, pp. 483-491, Nov. 2015.

[21] C. Julia et al., "Impact d'un système d'information nutritionnel simplifié sur les achats des consommateurs," Nutr. Clin. Métabolisme, vol. 31, no. 3, p. 228, Sep. 2017.

[22] W. Yanhui and N. H. E. Aoud, "Le besoin de réassurance: de la psychologie au comportement du consommateur Une investigation théorique appliquée au cas de la consommation alimentaire moderne," Rev. Gest. Organ., vol. 7, no. 1, pp. 1-8, Mar. 2015.

[23] J. H. Antil, "Socially Responsible Consumers: Profile and Implications for Public Policy," J. Macromarketing, vol. 4, no. 2, pp. 18-39, Dec. 1984.

[24] B. Geraldine, "A nouvelle ère, nouveau marketing?," http://www.e-marketing.fr/, juin-2009. [Online]. Available: http://www.e-marketing.fr/MarketingMagazine/Article/A-nouvelle-ere-nouveau-marketing-32353-

1.htm\#\&utm_source=social_share\&utm_medium=share button\&utm_campaign=share_button. [Accessed: 04Jan-2018].

[25] L. Wiart, "Comportement du consommateur éthique : le cas particulier de la consommation de produits d'origine animale. Quelle intégration de l'éthique animale dans les pratiques de consommation ?," L'IEP de Toulouse, 2014.

[26] The Body shop, "Forever Against Animal Testing," www.Thebodyshop.com. [Online]. Available: https://www.thebodyshop.com/about-us/against-animaltesting. [Accessed: 05-Jun-2018].

[27] B. Laperche and G. Lefebvre, "Stratégie environnementale, innovation et mutation des firmes, Abstract," Innovations, no. 37, pp. 127-154, Feb. 2012.

[28] "Encore plus Panda - Pressemitteilungen - Fiat Group Automobiles Press." [Online]. Available: http://www.fiatpress.ch/press/detail/235. [Accessed: 05Jun-2018].

[29] M. Boisset, "Les « Métaux Lourds » dans l'alimentation : quels risques pour les consommateurs ?," Médecine Mal. Métaboliques, vol. 11, no. 4, pp. 337-340, Jun. 2017.

[30] F. Marano and R. Guadagnini, "Les nanoparticules dans l'alimentation : quels risques pour le consommateur?," Cah. Nutr. Diététique, vol. 48, no. 3, pp. 142-150, Jun. 2013.

[31] Y. Tamura, "Migrant smuggling," J. Public Econ., vol. 94, no. 7, pp. 540-548, Aug. 2010.

[32] F. Marticotte and M. Arcand, "Schadenfreude, attitude and the purchase intentions of a counterfeit luxury brand," J. Bus. Res., vol. 77, pp. 175-183, Aug. 2017.

[33] D. Gaurier, "Les interdits alimentaires religieux: quel possible rapport avec une forme de sécurité alimentaire?," in Penser une dimocratie alimentaire, François Collart Dutilleul., vol. Vol I, Inida (Costa Rica), 2013, p. 413.

[34] F. Bertacchini, E. Bilotta, and P. Pantano, "Shopping with a robotic companion," Comput. Hum. Behav., vol. 77, no. Supplement C, pp. 382-395, Dec. 2017.

[35] M. A. B. Promentilla, K. B. Aviso, R. I. G. Lucas, L. F. Razon, and R. R. Tan, "Teaching Analytic Hierarchy Process (AHP) in undergraduate chemical engineering courses," Educ. Chem. Eng., vol. 23, pp. 34-41, Apr. 2018.

[36] K. P. Yoon and W. K. Kim, "The behavioral TOPSIS," Expert Syst. Appl., vol. 89, pp. 266-272, Dec. 2017.

[37] S.-T. Yuan, "A personalized and integrative comparisonshopping engine and its applications," Decis. Support Syst., vol. 34, no. 2, pp. 139-156, Jan. 2003.

[38] R. H. Guttman and P. Maes, "Agent-Mediated Integrative Negotiation for Retail Electronic Commerce," in Agent Mediated Electronic Commerce, 1998, pp. 7090.

[39] W.-P. Lee, "Towards agent-based decision making in the electronic marketplace: interactive recommendation and automated negotiation," Expert Syst. Appl., vol. 27, no. 4, pp. 665-679, Nov. 2004

[40] J. Ferber, Multi-Agent System: An Introduction to Distributed Artificial Intelligence, vol. 4. 2001. 